\title{
A.A. Бурматов*
}

\section{Смертность населения в Сибири накануне коллективизации}

\begin{abstract}
В статье рассматривается смертность населения в Сибири накануне коллективизации. Тенденции в демографической сфере изучаемого периода важны для понимания эволюиии населения и позволяют 8 дальнейшем оченить потери населения в ходе проведения коллективизации.
\end{abstract}

Ключевые слова: Сибирь, смертность, младенческая смертность, санитарное состояние, гигиена

\section{A.A. Burmatov}

\section{Population mortality in Siberia on the eve of collectivization}

The article deals with the mortality rate in Siberia on the eve of the collectivization. Demographic trends in the period under study are important for understanding the evolution of the population and allow to esteem the further loss of population during the collectivization.

Key words: Siberia, mortality, infant mortality, sanitary condition, hygiene

С началом восстановления народного хозяйства в годы нэпа произошло и улучшение показателей воспроизводства населения. Повсеместно наблюдалась компенсаторная волна, связанная с реализацией рождений, не осуществленных в предшествующие годы. Высокая рождаемость сочеталась со снижением смертности населения. В 1926 г. в городах Западной Сибири показатель смертности составил 24,5\%о, в 1927 г. - 23,3\%о, 1928 г. - 21\%о, а в 1929 г. - 22\%о. У сельского населения соответственно 25,9\%; 25,4\%; 22 \%о и 23\%о [1, с. 4; 2, с. 137]. В селах смертность была выше вследствие более высокой рождаемости и худшего медицинского обслуживания. Невысокий уровень грамотности способствовал низкому санитарному просвещению населения. Факт, который мог нивелировать влияние более высокого уровня жизни жителей Сибири. Повышенный уровень смертности в Сибири, чем в целом по стране, напрямую связан с худшими социально-бытовыми условиями и медико-санитарным обслуживанием. В 1927-1929 гг. естественный прирост был в городах - 23-25\%о и в селах - 31-36\% ежегодно. Население вошло в период демографического взрыва. Исследователи в годы нэпа считали, что увеличение темпов прироста населения вызвано уступками большевистского правительства традиционному образу жизни населения, как бы шагом назад от революционного времени.

В 1925 г. в РСФСР насчитывался 4271 врачебный участок. Однако в 21,3 \% волостей не имели врачей, а 42,3 \% - больниц. Лозунг «Ни одной волости без врача» не был реализован. По сравнению с дореволюционным периодом число врачебных участков возросло на $12 \%$, больниц - на 8 \%, коек в них - на $9 \%$ [3, с. 200]. Наибольшее число волостей, не имевших квалифицированных медицинских кадров, приходилось на Сибирь. Качество статистического учета в Сибири оставалось также хуже. ЦСУ РСФСР вносило поправки на недоучет естественного движения [4, с. 14]. В 1926 г. сведения о регистрации не предоставили шесть районов Барабинского округа Сибирского края $[1$, с. 38,39$]$. В первом полугодии регистрация не производилась только в одном из них. В остальных регионах органы ЗАГС собирали сведения о рождаемости и смертности и передавали в статистическую службу [5, л. 15, 15 об]. Барабинск не имел регистрации в органах ЗАГС с июля по декабрь 1926 г. [6, л. 43, 43 об]. Законодательно были установлены следующие сроки регистрации: для рождений двухнедельный срок, а смертей - трехдневный срок [7, с. 278, 284]. С 1925 г. установлена обязательная врачебная регистрация причин смерти в городах и городских поселениях, а также в значительном числе сел. Во всех этих местностях смерть регистрировали в отделениях загсов только на основании «Врачебного свидетельства о смерти» $[8$, с. 66, 67]. На практике не хватало квалифицированных медицинских кадров, осмотр часто производился формально. Грешили ошибками и сами собранные материалы: неправильно указывали причины смерти, возраст и даже пол умершего.

\footnotetext{
* Бурматов Александр Анатольевич (Куйбышев) - кандидат исторических наук, доцент кафедры психологии и педагогики Куйбышевского филиала ФГБОУ ВО «Новосибирский государственный педагогический университет». РФ, 632387, Новосибирская обл., г. Куйбышев, ул. Молодежная,7; научный сотрудник сектора историко-демографических исследований Институт истории СО РАН, 630090, Новосибирская область, г. Новосибирск, ул. Николаева, д. 8. E-mail: al-burmatov@, yandex.ru
} 
В 1926 г. был принят новый кодекс РСФСР о семье, запрещающий прерывание гестации у первобеременных и для женщин, сделавших аборт менее полугода назад. К 1928 г. население смогло адаптироваться к новому закону. Криминальные аборты становились серьезным бичом для общества. Появились стишки «После повитух быстренько испустишь дух». Медицинские работники провели анкетирование распространения аборта в деревне. А.Б. Генс, анализируя собранные анкеты, указывал, что в Новониколаевской губернии из 27 существующих врачебных участков данные предоставили 9 (33,3%), в Томской 10 из 37 (27,0 \%), в Иркутской 6 из 28 (21,4 \%), в Енисейской 19 из 43 (44,2 \%). Все участки предоставили результаты анкетирования в Омской (43 участка) и Алтайской губернии (31) [9, с. 19]. Наркомат здравоохранения констатировал на основании данных половины врачебных участков: «До сих пор наша политика по отношению к деревне заключалась в том, что мы как бы «не пускали» аборта в деревню... все равно крестьянка ищет своих путей и находит их у бабок...Больницы вынуждены были принять 66 тысяч загрязненных больных..., потеряли свыше 3000 женщин» [10, с. 5]. Врачи забили тревогу. IV съезд врачей в 1926 г. уделил большое внимание в борьбе с абортами. В основном докладе говорилось: «Вести линию на полное запрещение абортов в частной практике. В дополнение к имеющимся бесплатным койкам встать на путь разрешения платных коек для абортов в городах... Средства, полученные от эксплуатации этих абортных коек, направлять в специальный фонд ОММ (охрана материнства и младенчества. - А.Б.) и тратить их исключительно на борьбу с абортами, исключив мотив получения прибыли» [3, с. 214, 215].

Официальные требования к врачебным участкам были следующие. Для врачебно-амбулаторного (т.е. когда отсутствовала больница) - один врач, один санитарный врач, два лица среднего медперсонала, одна акушерка и одна сестра-обследовательница. Для врачебно-больничного участка - не менее двух врачей, одного зубного врача, одного санитарного врача, трех лиц среднего медицинского персонала, две акушерки, две сестры-обследовательницы, ухаживающего и хозяйственного персонала. В нем должно быть 16 коек (из них восемь общего, хирургического и терапевтического профиля, четыре родильных и четыре инфекционных) [11]. Статистика по Сибири свидетельствует, что медицинское обслуживание населения не соответствовало даже этим минимальным критериям. Нехватку врачей, медперсонала и денежных средств признавали на верху. Как писал крупный специалист по социальной гигиене, заместитель наркомздрава СССР 3.П. Соловьев: «Первым и главным лозунгом, осуществление, которого, даже при слабости материальных ресурсов, дает возможность проводить профилактические начала в деревне, будет жизненный и важный лозунг - второй врач на участок». С мест от населения поступали в Москву запросы с предложениями об улучшении медицинского обслуживания, в которых делался вывод: «Удовлетворение насущных нужд деревни считаем мы первоочередной задачей; но оздоровление населения одним только лечением без широкого участия самого населения в деле здравоохранения никогда не будет достигнуто, а это участие... можно вызвать только санитарным просвещением», - привел цитату из письма 3.П. Соловьев на Втором съезде участковых врачей в 1925 г. [12, c. 108, 109].

Власти реагировали на плохое медицинское обслуживание своеобразно. На заседании Барабинского окрисполкома рассматривался вопрос о состоянии здравоохранения в округе. В речи заведующего окружным здравотделом были отмечены расширение сети учреждений и увеличение числа медработников. Доклад подвергся критике со стороны представителей с мест. Делегат Кыштовского района заявил: «Вам здесь в городе хорошо, ибо у вас медпомощь оказывается более или менее удовлетворительно, не то совсем у нас в урмане, когда на 60 тысяч населения насчитывается всего 2 фельдшера и 2 акушера, а об аптеках и говорить нечего. За десятки верст приходится ездить за касторкой и бинтом». В ответ на критику было сказано, что главная проблема решается путем «изжития известного зажима средств здравоохранения со стороны некоторых риков» $[13$, с. 55,56$]$, т. е. недостаточное финансирование объяснили неправильным распределением средств на местах.

Качество воды во многих районах Сибири было низким. Это вызывало болезни, неоднократно принимавшие характер эпидемии. Плохое санитарно-гигиеническое состояние водоемов во многом вызывалось культурой населения. 17 июня 1927 г. Каинский горсовет принял постановление «О мерах против загрязнения источников», в котором запрещалось вываливать мусор на берегах реки, полоскание белья, вывоз навоза и т.д. $[13$, с. 56]. В Каинске «водокачка берет не фильтрованную воду из реки Оми (в документе указано ошибочно Оби. - А.Б.), вода которой не отличается высокими качествами [14]». Однако не предусматривалось никаких альтернативных мер по водоснабжению, очистке водоемов. В Татарском уезде, существовавшем в 1921-1925 гг. в составе Омской губернии, из 304 селений источником водоснабжения являлись: реки - в 26,4 \%, озера $21,9 \%$, колодцы - 33,1 \%, смешанное водоем и колодцы - 14,9 \%, болота - в 3,7 \%. В Татарске за питьевую воду жители платили 4,5 коп. золотом. Это было тяжелым бременем для населения [15, с. 32].

Снижение смертности сдерживали антисанитария и скученность: «Жилища коммунаров представляют собою отдельные маленькие крестьянские ветхие избы. Живут коммунары очень тесно, например, семья из 
10 человек живет в двух небольших комнатах площадью приблизительно в 12 кв. метров; на этой площади расположена и русская печь. ... С пола и дверей всегда дует. Двери даже примерзают внутри. Нет теплых уборных, нет хороших колодцев, квартиры в большинстве отапливаются русскими печками, но во многих домах стоят даже железные печки, от которых температура воздуха бывает очень высокая во время топки и с прекращением ее быстро падает, что вредно отражается на здоровье коммунаров». Отмечается, что «в квартирах холостяков... грязно ... Воздух везде спертый и накурено. Практикуется даже плевание на пол и бросание окурков. Грязь и спертость воздуха можно объяснить отчасти и теснотой помещения, в котором приходится жить и работать». Отсутствует смена белья, нет места для сушки белья и т.д. В квартирах семейных «очень много тараканов и клопов». Донесениями отмечается сплошная неграмотность колхозников и коммунаров и рост числа неграмотных $[16$, с. 11, 48]. Гигиенист К.М. Гречищев писал: «Все сельское население Сибири... доселе остается вне какого бы то ни было влияния санитарной культуры... У сельского населения Сибири нет запросов к гигиенической жизни и нет к этому навыков» [Цит. по: 17, с. 182].

На основе текущей статистики и итогов всесоюзной переписи населения 1923 г. для населения Сибири были рассчитаны таблицы ожидаемой продолжительности жизни. Мальчику-сибиряку предстояло прожить в 1926/27 гг. в среднем 39,18 года, а девочке - 43,20. Для обоих полов показатель составлял 41,12 года. Это было значительно меньше, чем в европейской части РСФСР, в которой мальчику предстояло прожить 40,23 года, девочке - 43,61 года, для обоих полов - 42,93 года. У горожан-сибиряков ситуация была тревожней: для обоих полов 37,57 года, у мальчиков - 34,88 года, у девочек - 40,60 года, В сельской местности ситуация складывалась благополучней 41,72; 39,93 и 43,61 соответственно [18, с. $8,134,136,138]$. В значительной мере влияло качество статистического учета (в селах недоучет был выше), но и сам образ жизни. Например, отдаленные села эпидемии посещали редко, там была меньшая скученность и потери от недугов. Выходцы из этих сел болели корью, оспой и прочими болезнями часто, как дети. Среди городского населения течение эпидемических заболеваний носит более тяжелый характер $[19$, с. 9, 10, 14]. Основными причинами смертности в крупных и промышленных городах Сибири в 1928-1929 гг. являлись инфекционные и паразитарные заболевания (25,2 25,4 \% всех смертных случаев), болезни органов дыхания (16,0-17,4 \%) и пищеварения (16,0-16,2 \%). Относительно редкими были причины смерти от сердечно-сосудистых $(8,2-8,4 \%)$ и онкологических $(5,0-5,6 \%)$ недугов. Смертность от внешних причин составляла 5,2 \% всех смертей, старческая дряхлость - 3,2-3,5 \%, преждевременные роды и пороки развития новорожденных - 4,9-5,5 \% [20, с. 64]. Структура смертности населения соответствовала началу демографического перехода. Смертность носила ярко выраженный сезонный характер. В докладах медицинских работников это получает четкую характеристику: «В жаркое летнее время среди детей грудного возраста отмечается значительное учащение желудочно-кишечных заболеваний и также резко выраженная сезонность, и массовость этого явления дает высокий процент летней смертности детей раннего возраста» [21]. Высокая смертность младенцев обеспечивала и повышенную общую смертность населения. В городах Сибири число умерших детей до года составляло 25,5-46,1 \% всех умерших, а в селах число не доживших до года - 46,7-60,4 \% от всех скончавшихся в деревне. Исследователи отмечают: «Во все годы наблюдается более высокая смертность мальчиков сравнительно с девочками. ... Приходится ввиду этого принять, что новорожденные мальчики повсюду появляются на свет более слабыми и менее жизнеспособными, чем девочки» [23, с. 300, 301].

Смертность населения в 1927-1929 гг. сохранялась на высоком уровне - 21-22 \%о. Некоторое ее повышение в 1928 г. связано с увеличением младенческой смертности $[1$, с. 53; 23, с. 139, 140; 26]. Большая часть смертей младенцев падает на летние месяцы. Статистики заметили, что «общий ход детской смертности в течение года таков, что лишь 3 летних месяца - июнь, июль и август - она превышает среднюю смертность всего года; однако за эти месяцы она достигает колоссального подъема (1600-1800, принимая годовую среднюю за 1000)» [22, с. 301]. В данное время часто умирали и дети 3-5 лет. Из-за высокой рождаемости доля таковых в населении была значительной, а скученность и антисанитария способствовали распространению заболеваний и эпидемий. Особенно много детских жизней уносили желудочно-кишечные расстройства - «детская холера», которая наступала в условиях жаркого и сухого лета. Крестьяне отмечали повышение смертности детей в летние месяцы (июль-август). Жительница д. Ефремовка Верх-Ичинского (ныне Куйбышевского) района Елена (Алена) Яковлевна Клименок (белоруска по национальности, как и большинство жителей этого населенного пункта) сообщала: «Як дрыстун (паслен горько-сладкий, ядовиты все части растения, цветет в середине июля августе) зацвяцець - мыт (изнуряющий понос) нападзець. Идзеш з поля - там скрынка (детский гробик), там».

По данным специальных исследований середины 1920-х гг. на летние месяцы падало 46 \% всех умерших детей до года, на осенние - 20 \%, на весенние и зимние - по 17 \%. На первый месяц жизни смертных случаев новорожденных приходилось в 2,3 раза больше, чем в среднем за месяц на первом году жизни [24, с. 64]. Медики констатируют сезонную смертность по всей стране. Власти уделяли большое внимание охране материнства и детства. Кроме медицинских мероприятий, основной упор делался на просвещение населения 
и ознакомление его с основами социальной грамотности. Руководство всей работой по охране материнства и младенчества СССР было поручено Центральному отделу Народного комиссариата здравоохранения, которое имело в губерниях соответствующие подотделы. Создавались комиссии содействия с целью широкой пропаганды идеи охраны материнства и детства среди работниц и крестьянок $[25$, с. 231, 232]. Исследователь Г.П. Синкевич отмечал, что младенцы находятся летом в темной и душной избе, и ребенок «становится рахитиком», а ребенку нужны свежий воздух и солнце. Няня-ребенок лет 6-8 нарушает запрет старших выносить младенца на улицу, заигравших по-детски. Убедить молодых в необходимости прогулок ребенка на свежем воздухе еще удается, но старуху-няню - не представляется возможным. «Бабушка находится в избе безвылазно». Мать находится целый день на поле, а вечером у нее «молоко перегорелое». «Летние помирали, а осенние жили»,- отмечали крестьянки [24, с. 66-77].

Исследователи периода нэпа осознавали, что главный резерв снижения смертности - это устранение смертности от инфекционных заболеваний. К этому времени четко наметилось снижение смертности от них. Медики отслеживали и оперативно реагировали на распространение заболеваемости. Принимались срочные меры по устранению причин, вызывающих эти недуги. Отмечается постоянный рост числа учтенных острозаразных заболеваний в Сибири. Число заболеваний в городах снижалось (за исключением 1928 г.), а в сельской местности постоянно росло. Это свидетельствует об улучшении статистического учета. Снижается заболеваемость малярией с 1925 по 1928 г. в 3,2 раза, оспой в 3 раза, сыпным и возвратным тифами. С 1926 по 1928 г. почти вдвое уменьшилась заболеваемость коклюшем, на $1 / 3$ - дизентерией. Отмечался рост заболеваемости гриппом, туберкулезом, столбняком и трахомой [26, с. 786-789]. Специалисты говорили «о постепенном из года в год нарастании обнаруженной заболеваемости» [27, с. 27]. Медики отмечали, что к основным опасным с социальной точки зрения относятся «заразные»: тифы, холера, скарлатина, оспа, туберкулез, сифилис. Борьба с ними является наиболее важной. Социально опасным признавался алкоголизм. Оздоровление жилища и источников воды крестьянина для медицинских кадров становились важнейшими задачами. Особый упор в медицинской практике делался на профилактику заболеваний, привитие навыков личной гигиены. Мероприятия объективно способствовали снижению смертности населения.

\section{Источники и литература}

1. Естественное движение населения в Сибкрае за 1925-1927 гг. Новосибирск: Сибкрайисполком, 1930. 95 с.

2. Слуцкий А. Предварительные итоги естественного движения в Сибкрае за 1928-29 гг. // Статистика Сибири. Новосибирск: Сибкрайстатотдел, 1930. Вып. 2. С. 176-186.

3. Конюс Э.М. Пути развития советской охраны материнства и младенчества (1917-1940). М.: Центр. ин-т усовершенствования врачей, 1954. 404 с.

4. Песчанский $B$. Основные показатели естественного движения населения РСФСР // Статистика и Народное хозяйство. М.: ЦСУ РСФСР, 1928. Вып. 1. С. 14-16.

5. Государственный архив Новосибирской области (далее - ГАНО). Ф. 11. Оп. 2. Д. 12. Л. 15, 15 об.

6. ГАНО. Ф. 11. Оп. 2. Д. 13. Л. 43, 43 об.

7. Уиппль Дж, Новосельский С.А. Основы демографический и санитарной статистики. М.: Госмедиздат, 1929. 683 с.

8. Мерков А.М. Демографическая статистика (статистика населения). М.: Медицина, 1965. 215 с.

9. Генс А.Б. Аборт в деревне. М.: Охрана материнства и младенчества, 1926. 48 с.

10. Лебедева В. Предисловие // Генс А.Б. Аборт в деревне. М.: Охрана материнства и младенчества, 1926. С. 3-10.

11. Горфин Д. Врачебный участок // БСЭ / гл. ред. О.Ю. Шмидт. М.: БСЭ, 1929. Т. 13. Стлб. 412-415.

12. Соловьев 3.П. Профилактические основы лечебного дела в деревне // Соловьев 3.П. Строительство советского здравоохранения. М.: Медгиз,1932. С. 96-123.

13. Новониколаевская губерния - Новосибирская область. 1921-2000. Хроника. Документы / отв. ред. И.С. Кузнецов. Новосибирск: Администрация Новосиб. обл., 2001. 326 с.

14. ГАНО. Ф. П-3.ОП. 2. Д. 513. Л. 23.

15. Волк В. Гидрография губернии // Омская губерния. Материалы к познанию производительных сил губернии. Омск: Омск. губ. экон. совещание, 1923. С. 14-35.

16. Политпросвет работа в совхозах и колхозах. Опыт работы. М.: Работник просвещения, 1930. 172 с.

17. Зверев В. А., Бурматов А. А. Народонаселение Барабы в 1925-1940 годах. Новосибирск: Изд-во НГПУ, 2019. 279 с.

18. Смертность и продолжительность жизни населения СССР. 1926-1927. Таблицы смертности. М.; Л.: Планхозгиз, 1930. $140 \mathrm{c}$.

19. Реченский С. Корь и ее профилактика. М.: Охрана материнства и младенчества, 1928. 40 с.

20. Слуцкий А. Причины смертности по городам Сибири // Статистика Сибири. Новосибирск: Сибкрайстатотдел, 1930. Вып. 2. С. 60-66.

21. Исторический архив Омской области. Ф. 1143. Оп. 1. Д. 24. Л. 127а.

22. Куркин П. И. Смертность грудных детей (статистический очерк) // Куркин П. И. Вопросы санитарной статистики. М.: Госстатиздат, 1961. С. 284-310.

23. Статистика в Сибири. Новосибирск: Сибкрайстатотдел, 1929. Вып. 1. С. 139-140. 
24. Синкевич Г.П. Вологодская крестьянка и ее ребенок. М.; Л.: Гос. медиц. изд-во, 1929. 90 с.

25. Гинзбург Б.С. Охрана материнства и младенчества // Руководство по санитарной грамоте. М.: Новая Москва, 1925.

C. $223-243$.

26. Сибирский край. Стат. Справочник. Новосибирск: Статсектор Крайплана, 1930. 804 с.

27. Блох И. Эпидемия гриппа в СССР и за границей // Вопросы здравоохранения. 1929. № 8. С. 24-30. 